\title{
Análisis comparativo de los documentales transmedia argentinos, Malvinas 30 y El feriante. Características y singularidades transmedia
}

\author{
Miguel Ángel Vilte \\ Universidad Nacional del Nordeste, Argentina \\ viltebosch@gmail.com \\ https://orcid.org/0000-0002-9769-9721
}

\section{Comparative analysis of the Argentine transmedia documentaries Malvinas 30 and El feriante. Features and transmedia characteristics}

\begin{abstract}
RESUMEN ABSTRACT
El artículo presenta un análisis comparativo de los documentales transmedia argentinos Malvinas 30, lanzado en abril de 2012 y El feriante, en circulación desde octubre de 2017. El objetivo fue analizar el abordaje de la temática en una planificación comunicacional transmedia, identificando elementos y características de la producción de las narrativas transmedia, a la vez que interpretar las transformaciones que se produjeron en la construcción de las narrativas y percibir futuros escenarios. De este modo, en una primera instancia se realizó un análisis descriptivo de cada documental transmedia, posteriormente se examinó conceptos referenciales teóricos, luego se realizó el análisis comparativo que permitió identificar categorías, similitudes y diferencias de los documentales objeto de análisis. Concluimos que los temas abordados con una estructura de narrativas transmedia nos permiten vislumbrar un paradigma que requiere de políticas que promuevan la producción local y regional para producir contenidos, además de fomentar el conocimiento

y desarrollo de procesos transmediáticos que favorezcan la generación de lenguajes híbridos y el análisis de las narrativas transmedia para interpretar sus implicancias e

This paper presents a comparative analysis of the Argentine transmedia documentaries Malvinas 30, launched in April 2012 and El feriante, in circulation since October 2017. The objective was to analyze the approach to the subject matter in a transmedia communicational planning, identifying elements and characteristics of the production of transmedia narratives, while interpreting the transformations that occurred in the construction of the narratives and perceiving future scenarios. Thus, in the first instance, a descriptive analysis of each transmedia documentary was carried out, followed by an examination of theoretical reference concepts, and then a comparative analysis that allowed identifying categories, similarities and differences of the documentaries under analysis. We conclude that the topics addressed with a structure of transmedia narratives allow us to glimpse a paradigm that requires policies that promote local and regional production to produce content, in addition to fostering knowledge and development of transmedia processes that favor the generation of hybrid languages and the analysis of transmedia narratives to interpret their implications and interact in new scenarios.
\end{abstract} interactuar en nuevos escenarios.

PALABRAS CLAVE

Narrativa transmedia; Documental transmedia; Convergencia digital; Producciones transmedia argentinas.
KEYWORDS

Transmedia narrative; Transmedia documentary; Digital convergence; Argentine transmedia productions. 


\section{Introducción}

Convivimos con profundos cambios a partir de la innovación tecnológica que nos modificó los hábitos de vida, las formas de trabajo, de comunicación, de generación de nuevos lenguajes y narrativas en escaso tiempo. Por lo tanto, nos encontramos en una cultura de convergencia digital que nos exige diferentes aprendizajes y prácticas para comprender e interactuar en las formas de narrar y comunicar.

Jenkins (2006) define transmediación a las historias que se desarrollan en múltiples plataformas mediáticas y cada una de ellas contribuye de forma distinta para nuestra comprensión del universo; a su vez afirma que "la narración transmediática se refiere a una nueva estética que ha surgido en respuesta a la convergencia de los medios, que plantea nuevas exigencias a los consumidores y depende de la participación activa de las comunidades de conocimientos. La narración transmediática es el arte de crear mundos" (p. 31). Pero también Renó (2020) expresa que en el transmedia no hay control absoluto de hacia dónde van los procesos y los discursos mediáticos, como también que no se sabe hasta dónde sigue la historia, especialmente sus consecuencias.

En este marco, en el presente trabajo se describe y analiza comparativamente dos documentales transmedia argentinos: Malvinas 30 de Alvaro Liuzzi y El feriante de Patricio Irisarri. La primera obra fue lanzada en abril de 2012, cabe mencionar que luego de varios años aún continúa produciendo información; mientras que la segunda obra fue lanzada en octubre de 2017.

Los documentales fueron seleccionados por distintos motivos: el documental transmedia Malvinas 30 por la relevancia de un acontecimiento muy sentido para lxs argentinxs, como la Guerra de Malvinas. El mismo busca reconstruir una historia que por aquellos años encontraba serias limitaciones para dar a luz verdades que fueron censuradas por el gobierno militar. En tanto que la segunda obra, El feriante, nos interesa porque busca dar visibilidad a una problemática social de personas privadas de libertad que se encuentra oculta y que no tiene prioridad en la agenda mediática. A su vez, se valora el acompañamiento y formación a personas privadas de libertad, pero también el trabajo de distintas instituciones que realizan un proceso de intervención para garantizar el derecho constitucional de reincorporarse a la sociedad, una vez cumplida la condena. Como también consideramos que reflejar el trabajo de un feriante es mostrar una salida laboral a partir de distintos oficios en espacios colectivos donde se promueve la economía social y solidaria. En ambos documentales transmedia se pone como eje central personas cuyas heridas en los distintos contextos, perduran para toda la vida.

Remarcando el interés de la temática abordada y la planificación comunicacional transmedia, a continuación, se realizará una descripción de los documentales transmedia, para luego proceder al análisis valiéndonos de conceptos referenciales de diferentes autores que abordan la temática.

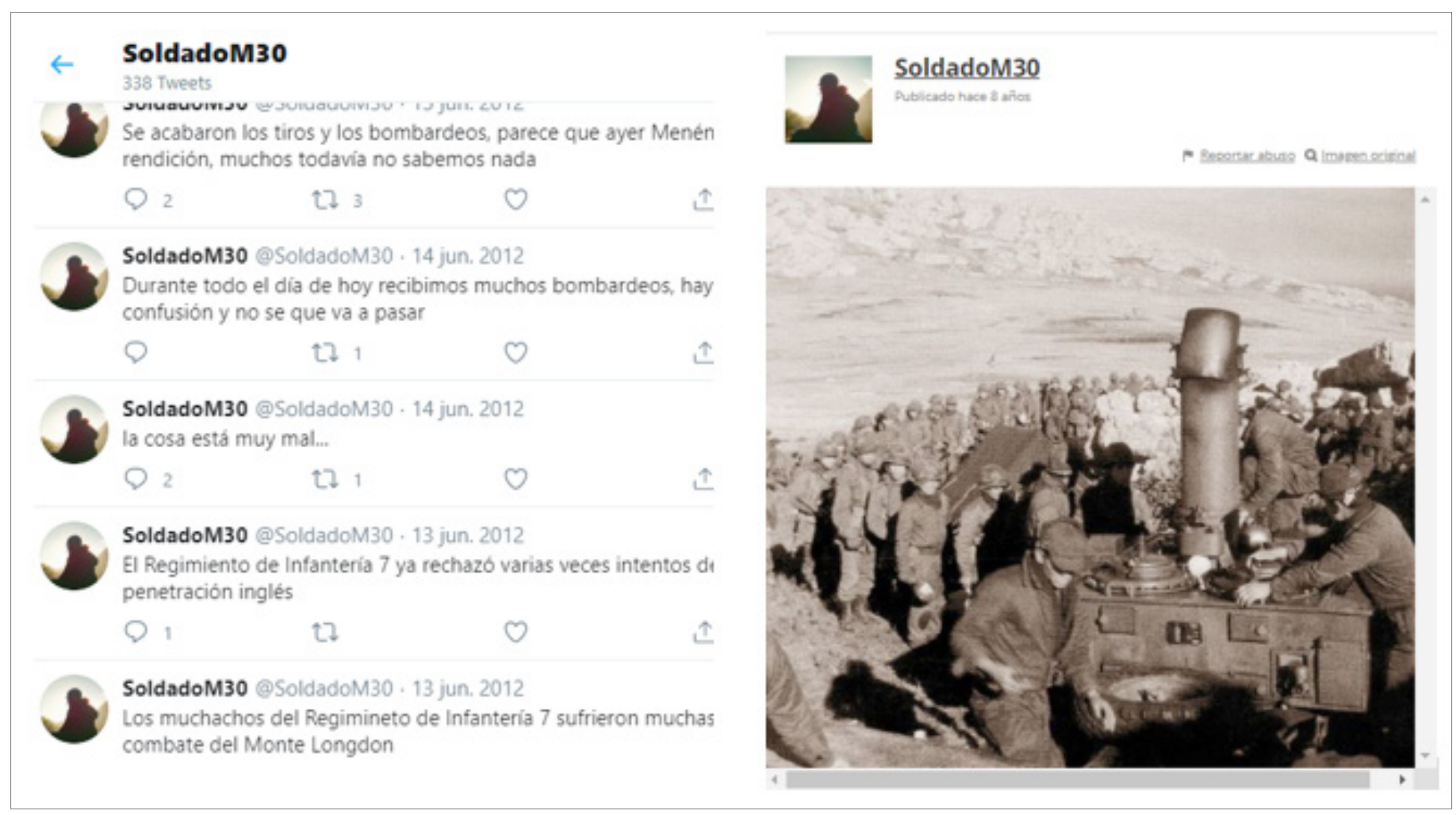

Figura 1. Ejemplo de relato en primera persona de recreación del conflicto bélico. También se planificó el uso de un sito para el registro de imágenes que reflejan el escenario en Malvinas. Fuente: perfil @SoldadoM30 en Twitter. 


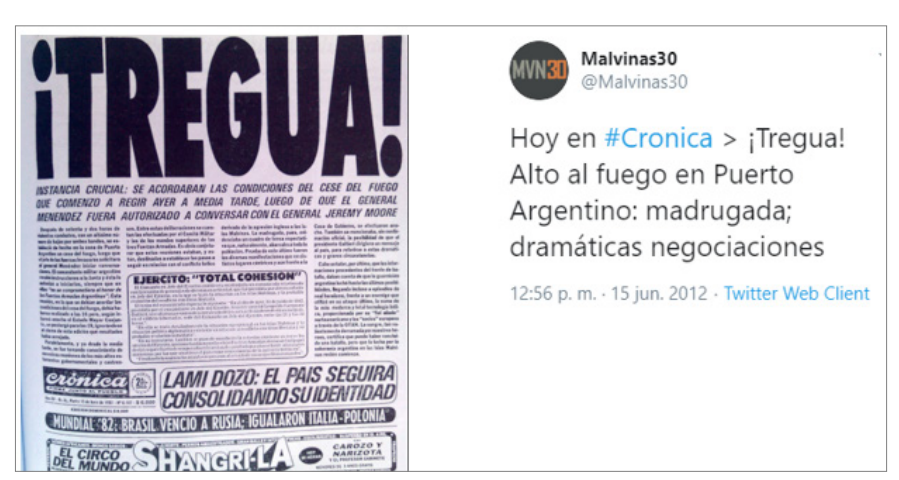

Figura 2. Publicación del diario Crónica sobre la situación crítica en Malvinas. Fuente: perfil @SoldadoM30 en Twitter.

\section{Documental: Malvinas 30, de Alvaro Liuzzi}

El documental Malvinas 30 cuenta con una estructura de producción transmedia y en tiempo real, luego de tres décadas del conflicto bélico en las Islas del Atlántico Sur entre Argentina e Inglaterra.

El documental, cuya producción se realizó a lo largo de meses en una búsqueda constante de interacción, permitió conformar una base documental de interés para concretar diversas producciones que permitieron extender el universo narrativo en distintas plataformas digitales.

La producción audiovisual no se encuentra en línea para su análisis. Sin embargo, se identificaron plataformas digitales, como Twitter, con los perfiles @Malvinas30 y @SoldadoM30, y Facebook, con el perfil Malvinas30. Por medio de los perfiles se estimula que los usuarios puedan revivir acontecimientos de la Guerra de Malvinas de 1982 como si fuese contada en tiempo real (figuras 1 y 2 ).

Las redes sociales mencionadas constituyen la herramienta fundamental del proyecto, que relata en primera persona y en todo momento busca la participación e interactividad con los usuarios. Es de interés el Twitter: @Malvinas30 que reconstruye la historia, complementa con información relevante y testimonial de aquellos días del conflicto bélico. Se destacan publicaciones en la prensa argentina e internacional (figuras 3, 4 y 5) y como también se identifican transmisiones por streaming de programas de televisión que muestran el posicionamiento y el manejo de la información en una época de gobierno militar.

En tanto que en el Twitter el perfil @SoldadoM30, sobresale el relato en primera persona de momentos vividos por el soldado clase 63 que refleja las injusticias cometidas y se contrapone en toda instancia con las publicaciones periodísticas de la época. El testimonio en primera persona, mediante tweets del soldado, busca interactividad con otros soldados y la ciudadanía en general, que aportan información valiosa en la plataforma, por lo que los testimonios, adquieren un rol protagónico, equiparable a una crónica, que refleja las injusticias cometidas con los soldados que defendieron nuestro país.

Con la finalidad de identificar las características de la construcción narrativa en diferentes plataformas, se seleccionó información encontrada en los sitios que reflejan los acontecimientos trascendentes en la guerra de Malvinas. Con los datos de referencia se intenta describir una etapa que nos tocó vivir.

\section{Nicolaides: «El Estado debe usar la fuerza'}

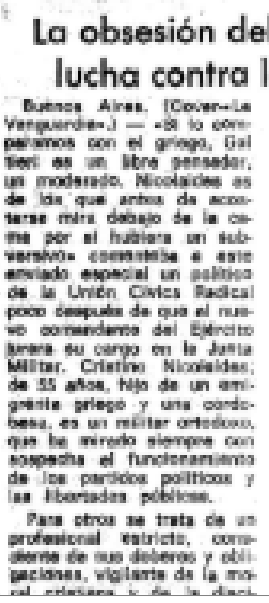

\section{Repatrían 5.500 prisioneros}

Jefes y oficiales no serán devueltos hasta el cese de hostilidades

Pese a que las repociacionss eatin on un momen to particularmente delicado, se han peodiceido , ya wh serie de hechos gue demuesiran que la tensión on el trisción de prisioneros es uns pruete evidente.

Lond es. ICrivess de sasstse

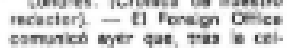
ds sel prenderit, Uationi, Ae.

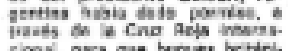
sons, pars que bects brutir. guritine loo omo ni prisiseceros

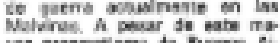
yer projnorima de sumen e.

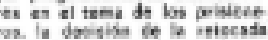

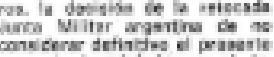
conkiters detinces el prapante

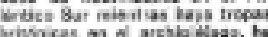
whsnces on a atchip wagn,

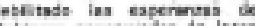

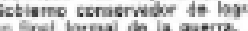

be les condiaess qua al m.

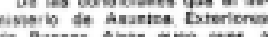
co Danse Aings ono ger, a

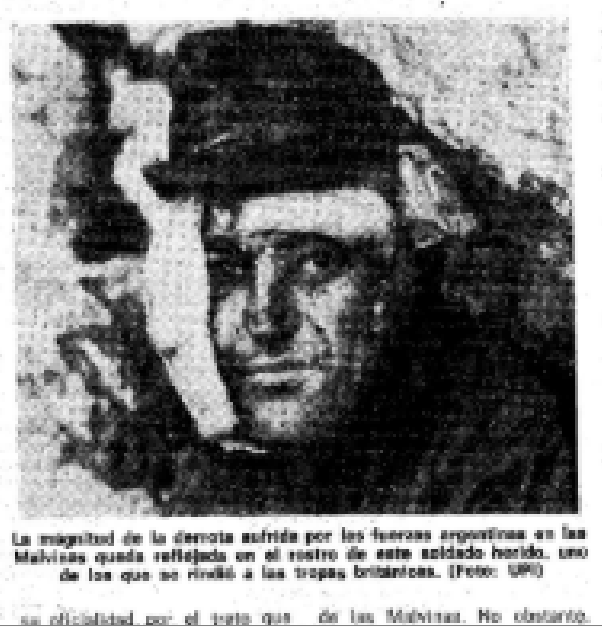

Figura 3. Publicación del diario español La Vanguardia que describe el escenario después de la derrota Argentina en Malvinas. 
Malvinas30@Malvinas30.18 jun. 2012

Hoy en \#Clarin > Cayó Galtieri. El general Nicolaides asume hoy como comandante en jefe del Ejército

\section{El general Nicolaides asume hoy como comandante ty en jefe del Ejército. is 1 \\ La Fuerzâ Aérea reclamó 2unrofundos cambios.

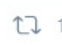 \\ ○ \\ $\uparrow$}

Q

Figura 4. Publicación del diario Clarín que se refleja la situación institucional del país ante la derrota en Malvinas.

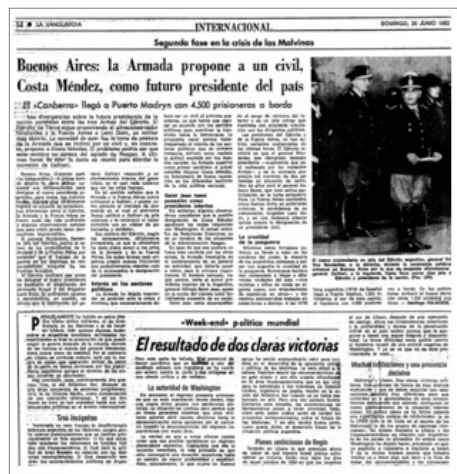

\section{MVNB: Malvinas 30 @Malvinas30 \\ Hoy en \#La Vanguardia > La Armada propone a un civil, Costa Méndez, como futuro presidente del país}

6:15 p. m. 20 jun. 2012 . Twitter Web Client

Figura 5. Publicación del diario español La Vanguardia que recoje la Propuesta de continuar en el poder del gobierno militar, en la persona del Embajador Costa Méndez.

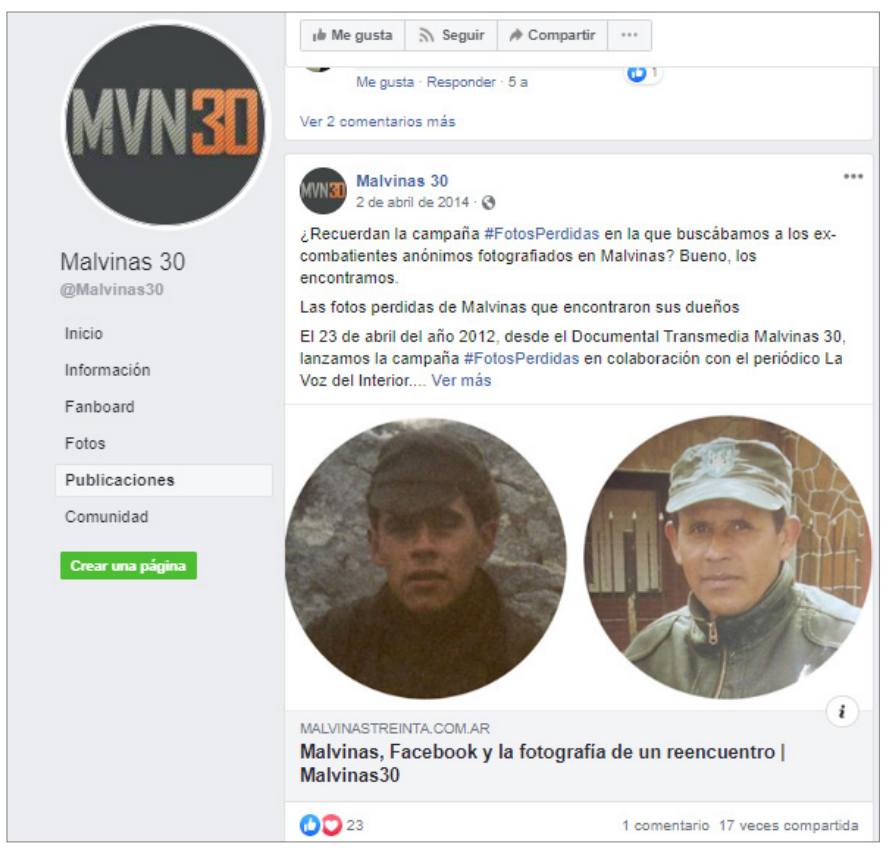

Figura 6. Publicación en Facebook del perfil Malvinas 30. Campaña para recuperar fotos pérdidas en articulación con el diario la Voz del Interior. Los resultados fueron positivos y permitió obtener documentación a raíz de la planificación.
En las diferentes piezas comunicacionales recuperadas se identifica una narrativa principal; adquiere relevancia el relato en primera persona, a la vez que la interactividad que se produce permite reunir documentación que retroalimenta la reconstrucción de un hecho histórico para el país. La documentación se transforma en pruebas valiosas, que a la vez, mantienen una estrecha relación en la construcción de las narrativas que se recrean, guardando interdependencia y complementariedad con el relato. De este modo, el documental que se ejecutó con una continua producción de cuatro meses, logró extender el relato a través de distintas plataformas digitales. Así se sensibilizó a los usuarios para que revivan la Guerra de Malvinas en distintos escenarios, que a modo ilustrativo en el presente trabajo se reconstruyó uno de los aspectos tan caros para la historia argentina.

\section{El Feriante}

El otro caso de análisis es el documental El feriante" de Patricio Irisarri. Es una producción transmedia que refleja la situación de las personas privadas de la libertad y que expresa en su sinopsis que "En Argentina, el grueso de la población detenida se ve afectada por el acceso relativo a un conjunto de derechos humanos inalienables. La mayor parte de los y las detenidas provienen de los sectores más postergados de la sociedad, condición que se acentúa hacia dentro de los muros y se reafirma en el egreso. El acceso a bienes culturales, a la producción simbólica y a los procesos creativos son restringidos, quizá de forma más aguda que otros derechos, para el sujeto encerrado"1.

Por otro lado, se expresa que en las cárceles de Rosario, Argentina, se realizan talleres de formación y producción de bienes culturales, donde talleristas e internos trabajan a la par, imaginan y trazan posibles trayectorias de vida en donde emerjan los deseos y las posibilidades, contrarrestando las privaciones propias de un sistema en crisis. Luego de esta breve descripción remarcamos que el interés por analizar la producción transmedia está centrado en la búsqueda de visibilidad de situaciones de vulneración a los Derechos Humanos que padecen las personas privadas de libertad, como también el abordaje de la reinserción laboral contemplado en nuestra Constitución Nacional. Y en forma especial nos interesa la planificación estratégica transmedia realizada.

Cabe destacar que en el documental transmedia participan distintos grupos de trabajo ligados a la Universidad Nacional de Rosario (UNR) que trabajan la problemática desde sus disciplinas, lo cual enriquece el tratamiento de la temática.

De este modo, la producción audiovisual tiene una estructura de cinco capítulos que, a partir de los testimonios del ex detenido Ángel, se invita a reflexionar sobre la vida de una persona privada de libertad y su búsqueda para reinsertarse en la sociedad, mostrando diversos aspectos que requieren de 


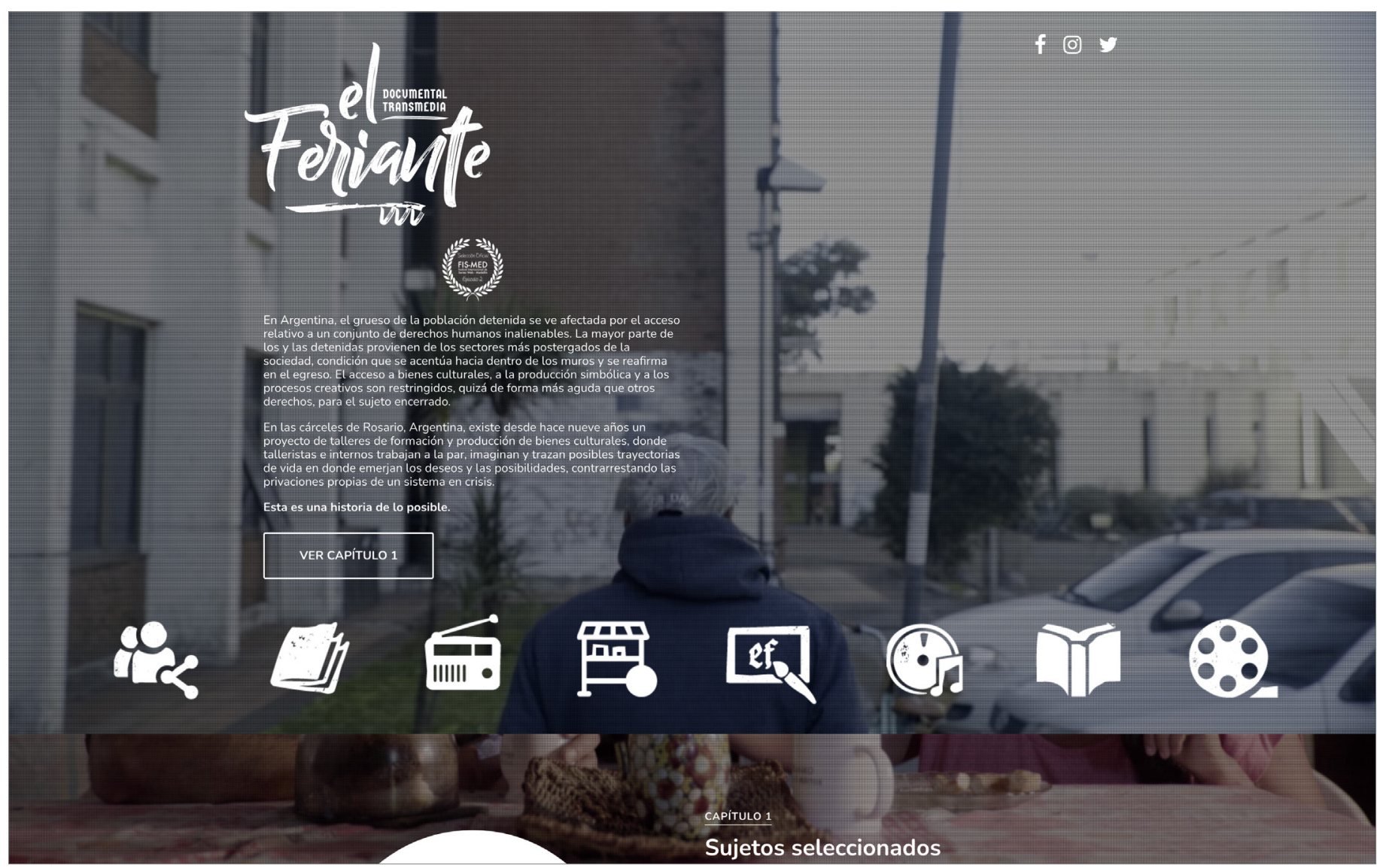

Figura 7. Interfaz principal de El Ferianate Fuente: http://elferiante.com.ar

abordajes interdisciplinarios para la comprensión de la realidad de personas en contextos de encierro. Se destaca el rol del protagonista Ángel en la búsqueda de reinserción laboral, a partir del trabajo artesanal con técnicas de mosaiquismo que aprendió en los talleres en una unidad penitenciaria.

El documental hace visible diferentes problemas que padecen los detenidos, a través de los espacios de talleres que se desarrollan en las unidades penitenciarias. Como también cada capítulo se encuentra articulado con audios, imágenes, videos, dibujos, revista digital, producciones audiovisuales de otros talleres, que en el conjunto de información refleja una realidad poco conocida. Con testimonios duros de la trayectoria de vida de los detenidos, desde la infancia hasta la actualidad, se caracteriza las principales dificultades que transitan las personas detenidas.

También se destaca una producción realizada en el Taller de Comunicación de la Unidad 3, "El fabricante de mujeres". Allí se narra que en un pueblo se había quedado sin mujeres y ya no producía cerezos (...), hasta que un artesano pone en marcha la fábrica de mujeres... La producción tiene como actores a los presidiarios. Por otro lado, se muestran prácticas de fútbol como actividad de recreación.

De este modo, se interpreta que los talleres buscan recrear a las personas detenidas a la vez que fomentan espacios de convivencia y reflexión de sus derechos en contextos de encierro.

Finalmente, el documental culmina con una fiesta organizada en la unidad penitenciaria donde se comparte los logros y resultados obtenidos en los talleres; también participan en el espacio músicos externos que colaboran con los detenidos y comparten momentos gratos en situación de encierro.

Además, en el sitio web, donde uno puede navegar eligiendo y construyendo su propio itinerario, se exhibe una imagen de Ángel en stand de la feria ofreciendo productos propios, también de compañeros de la unidad penitenciaria que Ángel comercializa. También, se exponen publicaciones institucionales que acompañan el proceso de reinserción laboral y en la sociedad. Allí mediante iconos se promueve la interacción con los usuarios. Cliqueando uno de los iconos se puede acceder a leer los contenidos de las publicaciones en una plataforma; como también el documental presenta interés desde la concepción de la planificación colectiva de la producción audiovisual con una construcción de narrativa transmedia que busca la expansión de los relatos en la sociedad, donde se pueden acceder a diferentes historias en distintas plataformas, que en el conjunto se logra visibilizar la problemática de las personas privadas de libertad, como también las instituciones que realizan un trabajo multidisciplinario que muchas veces no es reconocido por la sociedad. 


\section{El contexto de convergencia}

Por lo descripto precedentemente, destacamos que el tema abordado logra una planificación estratégica transmedia acorde al contexto de convergencia digital en el que convivimos. En ese sentido Jenkins (2006) apunta que

La convergencia mediática es más que un mero cambio tecnológico. La convergencia altera la relación entre las tecnologías existentes, las industrias, los mercados, los géneros y el público. La convergencia altera la lógica con la que operan las industrias mediáticas y con la que procesan la información y el entretenimiento los consumidores de los medios ( $p$. 26). La convergencia representa un cambio de paradigma: el paso de los contenidos específicos de un medio a los contenidos que fluyen por múltiples canales mediáticos, a la creciente interdependencia de los sistemas de comunicación, a los múltiples modos de acceder a los contenidos mediáticos, y a relaciones cada vez más complejas entre los medios corporativos de arriba abajo y la cultura participativa de abajo arriba. (p. 241)

Los contenidos del documental ofrecidos a usuarios transmediáticos en búsqueda de expansión, remarcan una clara estrategia comunicacional que tiene presente que la narrativa transmedia considera dos elementos según Scolari (2013), la expansión del relato a través de varios medios, y la colaboración de los usuarios en ese proceso expansivo. Al respecto afirma que "el relato donde la historia se despliega a través de múltiples medios y plataformas de comunicación, y en el cual una parte de los consumidores asume un rol activo en ese proceso de expansión" (p. 42).

En el caso del documental Malvinas 30, la expansión del relato se produce mediante las plataformas de twitter y facebook, pero adquiere relevancia la interacción que provoca en los usuarios que aportan documentación importante para la retroalimentación de la narrativa y la reconstrucción del proceso histórico. También se destaca otros sitios que alojan la información que se recupera.

Mientras que en términos de producción audiovisual de El feriante, se observa una significativa planificación participativa con diferentes actores institucionales involucrados en el proceso, que luego se ve reflejada en una arquitectura transmedia y en los resultados de la producción de contenidos transmedia, en una constante búsqueda de interacción con los usuarios.

Al respecto Renó (2020) expresa que

la sociedad pasaría a comunicarse de una manera tan líquida, no estructurada y libre de barreras físicas y/o conceptuales para construir sus procesos mediáticos particulares o independientes de los medios de comunicación masivos (..) De eso dependerán procesos y proyectos ajustados al nuevo ecosistema mediático, donde los ciudadanos ocupan un real estatus de protagonismo, de coautoría (p. 2). De este modo menciona que "transmedia como una narrativa, constituye un lenguaje cada vez más presente en el cotidiano ciudadano". (p. 4)

Pero la construcción de una narrativa transmedia se caracteriza por otros puntos fundamentales, como, por ejemplo, la planificación de las tramas y subtramas; además de las plataformas para la expansión de los contenidos, entre otros aspectos. En este sentido, es fundamental que el contenido tenga su difusión por redes sociales (Renó; Flores, 2012).

Por otra parte, (Renó; Ruiz, 2012) afirma que

además, es interesante que el contenido sea producido por dispositivos móviles, como teléfonos celulares y tablets. Finalmente, es interesante que tenga la posibilidad del actor prosumidor, conocido en los modelos tradicionales de comunicación como receptor, interactuando con el contenido; es decir, fundamentalmente construido a partir de conceptos de interactividad (p. 55); al producirse va cambiando, moviéndose y transformándose por sus múltiples autores, desde múltiples momentos y múltiples plataformas. Así pues, un mensaje transmedia no termina como tal: se transforma y se mantiene en potencia de continuar transformándose. (p. 56)

Por lo tanto, en el caso de la narrativa transmedia se puede hablar de informaciones-movimiento, donde ninguna de sus informaciones puede ser analizada como una pieza única, como un momento o un enfoque de la realidad que se cuenta, sino que en sí misma evidencia el transcurrir y la transformación de la experiencia de realidad de quienes la están construyendo (Renó; Ruiz, 2012: 56). Precisamente en el documental El feriante se observa no solo los cinco capítulos, sino la abundante información que se aporta en distintos formatos y plataformas que constituyen en su conjunto el interés de la narrativa transmedia como espacio propicio para la interacción con las audiencias.

De este modo, el documental busca, según Scolari (2013) que el relato se expanda por diferentes sistemas de significación y medios; así, "el relato se expande, aparecen nuevos personajes o situaciones que traspasan las fronteras del universo de ficción. Esta dispersión textual que encuentra en lo narrativo su hilo conductor -aunque sería más adecuado hablar de una red de personajes y situaciones que conforman un mundo- es una de las más importantes fuentes de complejidad de la cultura de masas contemporánea" (p. 19).

De esta manera, Ángel; los testimonios de los detenidos y los y las talleristas de distintos grupos e instituciones, se convierten en principales referentes para visibilizar situaciones de vulneración a los Derechos Humanos que padecen las personas privadas de libertad, como también adquiere preeminencia el abordaje de la problemática de reinserción laboral. Al respecto, Scolari (2013) expresa que "los actores del ecosistema mediático -empresas, tecnologías, profesio- 


\begin{tabular}{|c|c|c|}
\hline Categorías & Malvinas 30 & El Feriante \\
\hline $\begin{array}{l}\text { Estructura } \\
\text { narrativa }\end{array}$ & $\begin{array}{l}\text { La estructura narrativa está compuesta de géne- } \\
\text { ros híbridos. La narración se recrea en tiempo real } \\
\text { con un uso de redes sociales, especialmente Twit- } \\
\text { ter y Facebook en búsqueda de interactividad con } \\
\text { los usuarios. }\end{array}$ & $\begin{array}{l}\text { Se observa una estructura narrativa conformada por } \\
\text { una trama principal en cinco capítulos, pero también } \\
\text { subtramas, plasmadas en productos audiovisuales pro- } \\
\text { ducidos por distintos actores sociales que trabajan con } \\
\text { la problemática en contextos de encierro. }\end{array}$ \\
\hline $\begin{array}{l}\text { Historia } \\
\text { compartida en } \\
\text { fragmentos }\end{array}$ & $\begin{array}{l}\text { Se identifican relatos en primera persona; publi- } \\
\text { caciones en la prensa argentina e internacional, } \\
\text { como también se identifican transmisiones por } \\
\text { streaming de programas de televisión que muestra } \\
\text { el posicionamiento y el manejo de la información } \\
\text { en una época de gobierno militar. }\end{array}$ & $\begin{array}{l}\text { El documental se encuentra articulado con audios; imá- } \\
\text { genes; videos, dibujos, producciones audiovisuales de } \\
\text { otros talleres, que en el conjunto de información refleja } \\
\text { una realidad poco conocida. }\end{array}$ \\
\hline $\begin{array}{l}\text { Contenidos } \\
\text { distribuidos en } \\
\text { múltiples } \\
\text { plataformas }\end{array}$ & $\begin{array}{l}\text { A pesar que no se encontró en línea el documen- } \\
\text { tal, se identificaron las redes sociales de Twitter } \\
\text { y Facebook donde se identificó material valioso y } \\
\text { testimonios de la guerra de Malvinas. La decisión } \\
\text { de distribuir en múltiples plataformas garantizó } \\
\text { que los contenidos perduren en el tiempo. }\end{array}$ & $\begin{array}{l}\text { El documental presenta interés desde la concepción de } \\
\text { la planificación colectiva de la producción audiovisual } \\
\text { (participación activa de otros talleres en la produc- } \\
\text { ción de contenidos) con una construcción de narrativa } \\
\text { transmedia que busca la expansión en diferentes } \\
\text { plataformas. En el conjunto se logra visibilizar la pro- } \\
\text { blemática de las personas privadas de libertad. }\end{array}$ \\
\hline $\begin{array}{l}\text { Nudos } \\
\text { neuronales }\end{array}$ & $\begin{array}{l}\text { Al no encontrar en línea el documental que tiene la } \\
\text { trama principal, no se puede identificar los nudos } \\
\text { neuronales. }\end{array}$ & $\begin{array}{l}\text { Los nudos neuronales se identifican claramente en los } \\
\text { iconos que se exhiben en forma complementaria a cada } \\
\text { capítulo, permitiendo al usuario navegar libremente } \\
\text { creando un itinerario propio de fácil acceso. }\end{array}$ \\
\hline $\begin{array}{l}\text { Historia } \\
\text { expandida }\end{array}$ & $\begin{array}{l}\text { La interactividad de los usuarios, arrojó resultados } \\
\text { inesperados por los diseñadores del proyecto, ya } \\
\text { que no pueden controlar los alcances. A la vez que } \\
\text { se logró aportes de documentos (recortes perio- } \\
\text { dísticos; fotos testimoniales, etc.) para recrear el } \\
\text { escenario de la Guerra de Malvinas. }\end{array}$ & $\begin{array}{l}\text { Sin bien es cierto que el documental y las producciones } \\
\text { complementarias se encuentra en línea, no se obser- } \\
\text { van una estrategia marcada en busca de interactividad. } \\
\text { Al menos no se observa espacios que promuevan los } \\
\text { aportes de la ciudadanía. }\end{array}$ \\
\hline $\begin{array}{l}\text { Circulación por } \\
\text { redes sociales }\end{array}$ & $\begin{array}{l}\text { Sin duda la circulación de los contenidos y la } \\
\text { retroalimentación que se produjo, logró que lxs } \\
\text { ciudadanxs puedan aportar datos que de otro } \\
\text { modo, hubiesen sido imposibles de reunir. La for- } \\
\text { taleza del proyecto se radica en la interacción de } \\
\text { la ciudadanía que es protagonista y pasa a ser } \\
\text { coautora del proyecto por sus aportes a la recons- } \\
\text { trucción de la historia. }\end{array}$ & $\begin{array}{l}\text { En el sitio principal donde se aloja el documental y } \\
\text { las producciones audiovisuales complementarias de } \\
\text { características de transmedia, se observa al final las } \\
\text { redes sociales: Facebook: @ElFerianteDocumental } \\
\text { - Comunidad; Twitter @ElFeriante_; Instagran: elferian- } \\
\text { tetransmedia. En las redes se observan publicaciones e } \\
\text { interacciones, se destaca } 1.136 \text { seguidores en facebook. }\end{array}$ \\
\hline $\begin{array}{l}\text { Distribución } \\
\text { apoyada en la } \\
\text { estrategia "viral". }\end{array}$ & $\begin{array}{l}\text { La circulación por las redes sociales hizo que la } \\
\text { difusión se viralice para encontrar material para } \\
\text { reconstruir la historia sobre Malvinas. Prueba de } \\
\text { ello, son los aportes realizados por los ciudadanos } \\
\text { de las publicaciones en la prensa nacional e inter- } \\
\text { nacional. }\end{array}$ & $\begin{array}{l}\text { En las redes mencionadas se promueven los distintos } \\
\text { productos comunicacionales. Se destaca la promoción } \\
\text { de la revista digital en una plataforma dedicada a este } \\
\text { tipo de formatos. }\end{array}$ \\
\hline $\begin{array}{l}\text { Adopción como } \\
\text { herramienta } \\
\text { de producción } \\
\text { dispositivos } \\
\text { móviles (celula- } \\
\text { res y tablets). }\end{array}$ & $\begin{array}{l}\text { La disponibilidad del material se puede acceder } \\
\text { desde diversos dispositivos. Por lo que el diseño } \\
\text { está pensado en disponer de diferentes pantallas. }\end{array}$ & $\begin{array}{l}\text { Los contenidos transmedia se pueden acceder desde } \\
\text { distintos dispositivos. }\end{array}$ \\
\hline Planificación & $\begin{array}{l}\text { Se observan microhistorias complementarias } \\
\text { entre sí en las redes sociales. }\end{array}$ & $\begin{array}{l}\text { Se destaca la planificación de las tramas y subtramas } \\
\text { del documental en una estructura de narrativa trans- } \\
\text { media, con una participación activa de los actores } \\
\text { institucionales que intervienen en el tratamiento de la } \\
\text { problemática. }\end{array}$ \\
\hline $\begin{array}{l}\text { Identidad } \\
\text { (visual) }\end{array}$ & $\begin{array}{l}\text { No se percibe una identidad visual en las redes } \\
\text { sociales que se utilizan para la expansión. }\end{array}$ & $\begin{array}{l}\text { Se observa una identidad visual que se mantiene a lo } \\
\text { largo de las producciones audiovisuales, como también } \\
\text { en las redes sociales. }\end{array}$ \\
\hline
\end{tabular}

Tabla 1. Análisis comparativo. A partir de Vicente Gosciola (2003), Renó y Flores Vivar (2012) y Renó (2020). Elaboración propia. 
nales, lenguajes- tienden a converger, a acercarse entre sí y a hibridarse; inmediatamente después la fusión de esos actores genera contenidos -en nuestro caso las NT- que se propagan a través de todo el ecosistema" (p. 62). Una clara expresión de producción colectiva que parece no encontrar frontera para dar visibilidad a una problemática presentada con una arquitectura de narrativa transmedia que seduce la exploración de sus contenidos.

En ese ecosistema, en la Web 2.0 y ahora en Web 3.02, crece la participación de la sociedad en la construcción de contenidos informativos, es el caso de Malvinas 30, que reúne información precisa para reconstruir el escenario de la Guerra de Malvinas. Al respecto Dan Gillmor (2005) afirma que la sociedad contemporánea necesita tener un espacio de difusión para informaciones y que todo esto se puede crear en la blogosfera. En tal sentido, Renó (2011) manifiesta que a partir de la posibilidad de elaborar un espacio virtual en la blogosfera lxs usuarixs se convierten en gestores de los medios, junto con los canales convencionales, pasan a definir lo que es noticiable para la agenda general y global donde se posicionan los principales contenidos. A su vez expresa que "todo esto sucede por la fuerza de la circulación de contenidos a partir de las redes, esencialmente, entre los grupos sociales formados por estos sitios. De ahí que, el lector, por su parte, asume el papel de colaborador o coautor del contenido" (Renó, 2011, citado en Renó y Flores Vivar, 2012: 39). En el documental Malvinas 30, los ciudadanos definen la información a difundir, convirtiéndose en coautores, utilizando los espacios mediáticos disponibles y generando otro punto de vista para el análisis de una situación que fue adversa por muchos años para quienes combatieron en Malvinas.

Así, Renó y Flores Vivar (2012) expresan que "la blogosfera es formada por espacios abiertos, donde las personas pueden escribir en su espacio real-virtual y al mismo tiempo dejar abierta la posibilidad de los comentarios en sus posts. Así mismo, construye una red de usuarios interesados que comparten temáticas u opiniones y también hacen que la información circule entre ellos. Existen sitios de búsqueda de otros blogs, por temática" (p. 60). Entonces allí la construcción de la información tiene sentido porque su fuente de alimentación es la ciudadanía que defiende sus propios intereses en un contexto de convergencia digital.

\section{Análisis comparativo}

A los efectos de realizar un análisis comparativo recurrimos a la caracterización de la narrativa transmedia del investigador brasileño sobre medios digitales y narrativa transmedia, Vicente Gosciola, como también se contempló los aportes de Denis Renó. Con estas características se procedió a realizar las comparaciones de los documentales transmedia.

\section{A modo de conclusión}

Podemos mencionar que en los documentales transmedia analizados se destacan los temas abordados en estructuras narrativas que permitieron en el documental Malvinas 30 recuperar documentos importantes para reconstruir la historia, teniendo presente que, en un gobierno militar, la información era controlada y restringida la difusión. Mientras que en el caso del documental El feriante, el abordaje de la problemática de personas privadas de la libertad y su reinserción laboral una vez cumplida la condena, tiende a dar visibilidad a una compleja situación que requiere de la intervención interdisciplinaria para su tratamiento. De este modo, decimos que los temas son claves estructurados en tramas y subtramas que permiten un análisis acabado, pero también con la posibilidad que lxs usuarixs realicen aportes enriqueciendo la propuesta y hasta crear otras nuevas versiones sobre el tema de análisis.

Por otro lado, se observa como fundamental en el proceso de producción audiovisual, la planificación de la narrativa transmedia, que transforma las estructuras narrativas al proponer diversos mensajes presentados en diversas plataformas de lenguaje, independientes entre sí, pero relacionados y que en conjunto construyen un nuevo contenido (o significado) Renó (2020). El documental El feriante cumple acabadamente con ese propósito.

De esta manera, la instancia de definir las tramas y subtramas que contengan diversas historias tratadas con diferentes lenguajes de acuerdo a los soportes mediáticos elegidos; los nudos neuronales ${ }^{3}$ que permiten una navegación física, geográfica y cognitiva entre los mensajes, algunos de ellos interactivos y colaborativos; las diversas pantallas por las que se podrán acceder a los contenidos; la interactividad; la identidad, entre otros aspectos, resultan claves para facilitar al usuario (ciudadano/a) la posibilidad de explorar información mediante la navegación e interactividad en una estructura transmedia diversa que posibilite conocer y recrear historias, como en los casos analizados, con directa correlación al ejercicio de la ciudadanía, pero también permitir profundizar el conocimiento y el acceso a la información en un contexto de convergencia digital.

En este proceso de construcción "el modelo de lenguaje proporcionado por la narrativa transmedia atiende a las expectativas ofrecidas por los teléfonos móviles, como la interacción y la interactividad (cosas distintas, aunque parecidas), la participación, la movilidad en sí, la posibilidad de producción de contenidos en diversos formatos (video, audio, foto, etc.) y la conexión en tiempo real" (Renó, 2020b, p.2). Estos soportes que no detienen su desarrollo, nos lleva a un escenario donde las innovaciones tecnológicas moldean nuevos lenguajes y 
narrativas.

Al respecto Landow (2009) decía que "la aparición de cualquier tecnología nueva informacional, como por ejemplo el hipertexto, proporciona las condiciones para un mayor cambio social, aunque todo cambio, como los efectos democratizadores de la escritura, Lleva milenios. Tales cambios de regímenes informacionales siempre producen pérdidas y ganancias" ( $p$. 55). Por otra parte, afirma que "el texto electrónico es conectable, lo cual permite siempre que sea incorporado a redes electrónicas, como el hipertexto y la World Wide Web" (p.66). Teniendo presente las características de la textualidad digital, la velocidad exponencial en la obtención de información, siendo los buscadores herramientas que proporcionan la información requerida casi instantáneamente" (Landow, 2009).

En efecto, hoy nos encontramos en una diversidad de formatos, así como de posibilidades de acceso, consumo e integración funcional del contenido digital que se traduce en audiencias crecientes. Allí "la convergencia entre el ecosistema del hardware/software y el ecosistema mediático se resume en una paradoja sin precedentes: la crisis de las industrias del contenido viene a coincidir con un estallido de la demanda de contenido y de la diversidad de ámbitos y formas de consumo cultural" (Aguado, 2013, p.14).

Trabajar con el paradigma correcto, esto es, concibiendo los medios digitales en los términos apropiados, es esencial si se quiere aprovechar su especial capacidad. El paradigma, en otras palabras, es más importante que la nueva adquisición. Landow (2009) señala que "podríamos añadir que el uso de la tecnología de la comunicación es también la concreción de ciertos supuestos políticos" (p. 420). Por estas razones consideramos que las narrativas transmedia desarrolla nuevas capacidades de prosumidores que intervienen en entornos virtuales generando lenguajes y narrativas hibridas propias de un paradigma tecnológico digital. Por lo que se requiere acompañar en las acciones cotidianas el abordaje y el análisis de estos procesos, como también el desarrollo de políticas que respalden la producción de contenidos audiovisuales desde una perspectiva local y regional, a la vez que permita la inclusión de sectores postergados a los entornos virtuales por diferentes razones, para de este modo, encontrarnos en un mismo pie de igualdad en una sociedad democrática.

\section{Notas al final}

1. Recuperado de: http://www.elferiante.com.ar/

2. Web 3.0 es una expresión que se utiliza para describir la evolución del uso y la interacción de las personas en internet a través de diferentes formas entre los que se incluyen la transformación de la red en una base de datos, un movimiento social para crear contenidos accesibles por múltiples aplicaciones.

3. Enlaces similares al funcionamiento de las redes neuronales del cerebro que operan a grandes rasgos como los núcleos de actividad que se encuentran en nuestro entorno, como pueden ser en una navegación por distintos enlaces en la que consumimos o producimos contenidos, esto último, pone en cuestión la autoría de los contenidos.

\section{Bibliografía}

Aguado, J. (2013). La industria del contenido en la era Post-PC: Horizontes, amenazas y oportunidades. En Canavilhas, João (Org.). Notícias e Mobilidade: O Jornalismo na Era dos Dispositivos Móveis. (pp. 5-32) Livros Labcom.

Campalans, C., Renó, D.y Gosciola, V. (Ed.) (2012). Narrativas transmedia. Entre teorías y prácticas. UOC - Universidad Nacional de Rosario.

Gillmor, D. (2005). Nós, os media. Presença.

Gosciola, V. (2003). Roteiro para as novas mídias: do game à TV interativa. Senac. Sao Paulo

Herrera Castellanos, M. (2019). Reseña Bibliográfica "El feriante" documental transmedia. Revista Alquimia Educativa, 6(1), 187219-224.

Jenkins, H. (2006). Convergence Culture. La cultura de la convergencia de los medios de comunicación. Paidós Ibérica.

Jenkins, H. (2009). Cultura da convergência (2a edição). Aleph.

Landow, G. P. (2009) Hipertexto 3.0 La teoría crítica y los nuevos medios en una época de globalización. Paidós Ibérica.

Luzzi, Alvaro (2012). _Malvinas/30. Docubase. Mit open Documentary Lab. https://docubase.mit.edu/project/malvinas-30/

Moreno, Valentina (2013). Malvinas 30: Un Documental Transmedia Interactivo. Inter-docs. http://www.inter-doc.org/malvinas-30-un-documental-transmedia-interactivo/

Renó, D. y Ruiz, S. (2012). Reflexiones sobre periodismo ciudadano y narrativa transmedia. En Campalans, C., Renó D. y Gosciola, V. (ed.) (2012). Narrativas transmedia. Entre teorías y prácticas Un estudio de y sobre cultura política. Universidad Nacional de Rosario.

Renó, D. y Flores Vivar, J. M. (2012) Periodismo Transmedia. Fragua.

Renó, D. (2020a). El ADN de las narrativas transmedia. Universidad Nacional de Rosario.

Renó, D. (2020b). La nueva ecología. Universidad Nacional de Rosario.

Scolari, C. (2013) Narrativas Transmedia. Cuando todos los medios cuentan. Deusto.

\section{CV}

Miguel Ángel Vilte. Licenciado en Comunicación Social, Universidad Nacional del Nordeste (UNNE). Especialista en Docencia Universitaria (UNNE); especialista en Comunicación Digital, Universidad Nacional de La Plata (UNLP). Magister en Relaciones Internacionales. Fundación Democracia, Argentina - Universidad Internacional Tres Fronteras del Paraguay. Doctorando en Ciencias Sociales. Universidad Nacional de Jujuy (UNJu). Docente investigador Facultad de Humanidades, UNNE. 